\title{
Clinical Application of Platelet-Rich Fibrin in Pediatric Dentistry
}

\author{
Sowndarya Gunasekaran ${ }^{10}$ Soundarya Sakthivel ${ }^{20}$ \\ Vidhya Vijayan ${ }^{30}$ \\ 1 Department of Paediatrics and Preventive Dentistry, Vinayaka Mission's \\ Sankarachariyar Dental College, Vinayaka Mission's Research Foundation \\ Deemed to be University, Ariyanoor, Salem, India \\ ${ }^{2}$ Department of Oral Medicine and Radiology, AB Shetty Memorial \\ Institute of Dental Sciences, Nitte (Deemed to be University), \\ University, Mangalore, India \\ ${ }^{3}$ Department of Paediatrics and Preventive Dentistry, Coorg Institute \\ of Dental Sciences, Kodagu, Karnataka, India \\ J Health Allied Sci ${ }^{\mathrm{NU}}$ 2022;12:186-190.
}

\author{
Shanthala B. M. ${ }^{3(1)}$ George Babu3 ${ }^{3}$
}

Address for correspondence Sowndarya Gunasekaran, Assistant Professor, Department of Paediatrics and Preventive Dentistry, Vinayaka Mission's Sankarachariyar Dental College, Vinayaka Mission's Research Foundation Deemed to be University, NH 47 Sankari Main Road, Ariyanoor, Salem 636308, India (e-mail: drsowndaryag@vmsdc.edu.in).

\author{
Abstract \\ Keywords \\ - apexogenesis \\ - direct pulp capping \\ - regenerative \\ endodontics \\ - scaffolds \\ - platelet-rich plasma
}

Platelet-rich fibrin (PRF) is a fibrin matrix in which platelet cytokines, growth factors, and cells are trapped and may be released after a certain time and that can serve as a resorbable membrane. It can be obtained from blood with the help of a simple process. PRF is basically a concentrate of growth factors that promote wound healing and regeneration, which is used in various disciplines of dentistry to repair various lesions and regenerate dental and oral tissues. Although the use of PRF is well-documented, its use in pediatric dentistry remains unexplored, due to its restrictions and on account of the fact that it is a blood-derived product. PRF has been used globally to enhance tissue healing. This article provides an insight into the use of PRF in pediatric dentistry, its benefits, limitations, and recommendations.

\section{Introduction}

Platelet-rich fibrin (PRF) has been used in dentistry for more than a decade now. Its application in pediatric dentistry can be vital, but it has not been explored. PRF is an autologous product that contains elevated levels of nonactivated, functional intact platelets within a fibrin matrix that releases a relatively constant concentration of growth factors over a few days. Immediately after drawing blood, it is centrifuged, and PRF is produced. It is vitally used in regeneration of hard tissue such as continued root formation, healing after disimpaction, and healing after soft-tissue damage such as gingival surgeries. The production of PRF is easy but the major concern arises in drawing blood from pediatric patients. PRF's application in pediatric dentistry varies from pulp capping and pulpotomy to apexogenesis and healing of extraction socket. Review of literature on the use of PRF in pediatric dentistry is sparse. Studies using bioactive materials containing host's endogenous growth factors represent a paradigm shift from the conservative clinical approach to more predictable regenerative solutions in dentistry.

\section{Platelet-rich Fibrin}

PRF is a bioactive surgical additive material prepared from the centrifuging patient's whole blood, a second-generation platelet concentrate described by Choukroun et al. ${ }^{1} \mathrm{PRF}$ is used to accelerate tissue healing. PRF is a simple and nonexpensive chairside process that results in a resorbable fibrin matrix, supplemented with rich platelets and leukocytes. It
DOI https://doi.org/ $10.1055 / \mathrm{s}-0041-1736269$ ISSN 2582-4287.

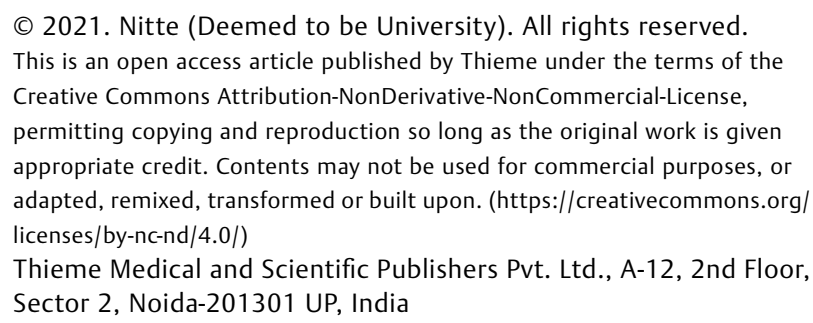




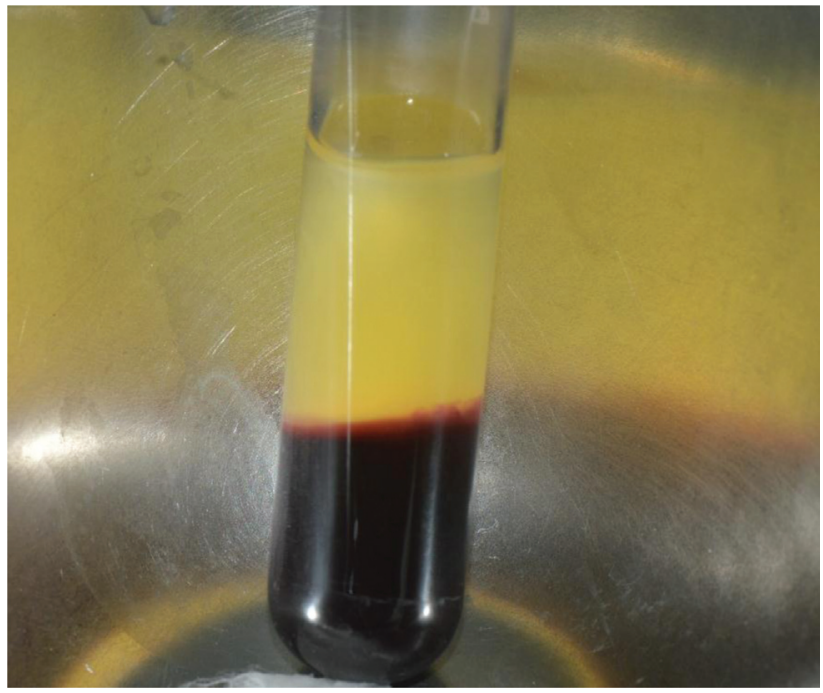

Fig. 1 Platelet-rich fibrin (PRF) in test tube after centrifuging showing platelet-poor plasma, PRF clot, and red blood cells (RBCs).

provides a rich source of growth factors, which includes platelet-derived growth factors, transforming growth factors, vascular endothelial growth factor, and insulin-like growth factor. ${ }^{2}$ The growth factors are gradually released during the time of the healing. PRF is used in dentistry due to its unique healing potential. ${ }^{3,4}$

\section{Preparation of PRF}

Preparation for PRF production follows a standard protocol, as described by Choukroun et al. ${ }^{1} \mathrm{~A}$ total of $5 \mathrm{~mL}$ of whole venous blood is drawn with anticoagulant in $10 \mathrm{~mL}$ tubes and immediately centrifuged at 3000 rotations per minute (rpm) for 10 minutes. The blood is contacted with the test tube wall during the centrifuging process, leading to the activation of

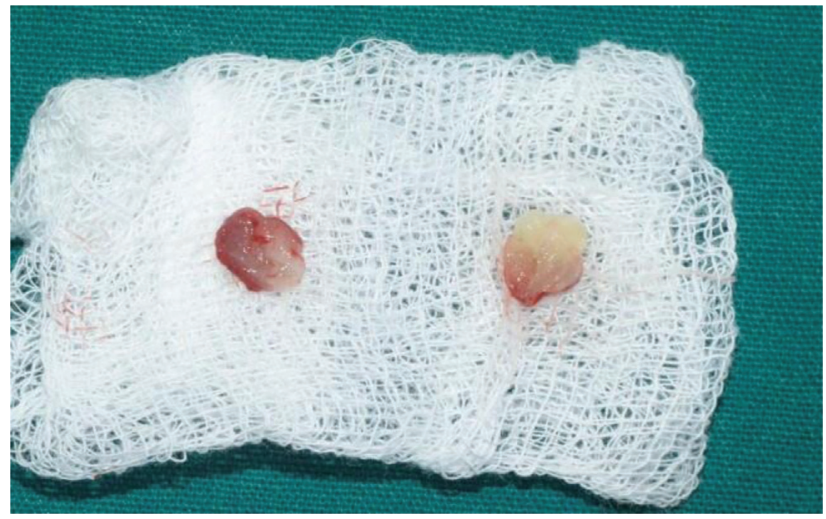

Fig. 2 Platelet-rich fibrin (PRF) is squeezed between the sterile gauze pads.

platelets which, in turn, in turn initiate coagulation cascade. The resultant product will consist of three layers (-Fig. 1):

- Platelet-poor plasma.

- PRF clot.

- Red blood cells (RBCs).

Fibrinogen, which is concentrated on the higher part of the tube, is converted into fibrin by the circulating thrombin, thus the platelet-trapped fibrin clot is formed in the middle, RBCs at the bottom, and acellular plasma at the top. The PRF is then removed from the test tube using surgical tweezers and separated from other layers using sterile scissors. PRF is squeezed between the sterile gauze pads ( - Fig. 2) to obtain a membranous film, which can be packed into the tooth for specific procedures.

\section{Constituents of PRF}

Growth factors released from PRF have been cited in - Table 1.

Table 1 Growth factor cells present in PRF and their function ${ }^{5,6}$

\begin{tabular}{|l|l|}
\hline Cells & Functions \\
\hline Interleukin 1 & Key moderator of inflammation control and stimulates T-helper lymphocytes \\
\hline Interleukin 6 & Activates B lymphocytes, stimulates secretion of antibodies \\
\hline Interleukin 4 & $\begin{array}{l}\text { Aids in multiplication and differentiation of activated B lymphocytes. Aids healing by } \\
\text { controlling inflammation }\end{array}$ \\
\hline Tumor necrosis factor- $\alpha$ & Activates monocytes, stimulates remodeling capacities of fibroblasts \\
\hline $\begin{array}{l}\text { Cytokine vascular endothelial } \\
\text { growth factor }\end{array}$ & Promotes angiogenesis \\
\hline Platelet-derived growth factors & Maintains migration, multiplication and endurance of mesenchymal cell lineages \\
\hline Insulin-like growth factor & $\begin{array}{l}\text { Cell proliferation arbitrator in apoptosis, employs chemotactic results against human } \\
\text { osteoblasts }\end{array}$ \\
\hline Transforming growth factor $\beta 1$ & $\begin{array}{l}\text { Triggers multiplication of fibroblasts and periodontal ligament cells, amplifies collagen } \\
\text { manufacture }\end{array}$ \\
\hline Vascular endothelial growth factor & $\begin{array}{l}\text { Supports the cohesion of the endothelial cell lining of the blood vessel and stimulates } \\
\text { neoangiogenesis throughout the wound healing }\end{array}$ \\
\hline Fibroblast growth factor & $\begin{array}{l}\text { Controls ectodermal origin cells and demonstrates chemotactic and mitogenic efforts } \\
\text { on periodontal ligament fibroblast cells }\end{array}$ \\
\hline
\end{tabular}

Abbreviation: PRF, platelet-rich fibrin. 


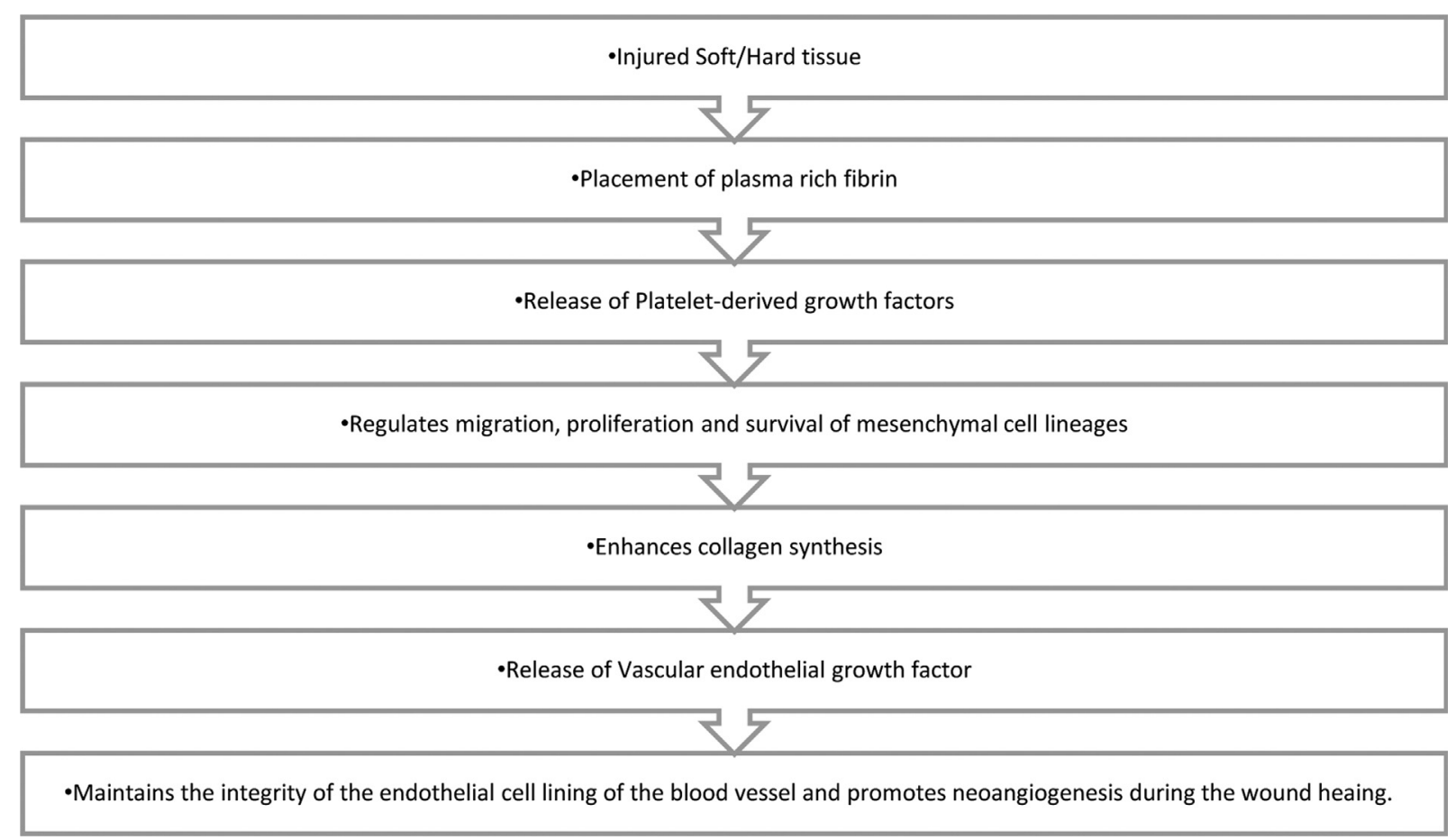

Fig. 3 Mechanism of action of platelet-rich fibrin (PRF) in wound healing.

\section{Mechanism of Action}

PRF aids in wound healing mainly through the action of growth factors, ${ }^{5-10}$ which are present in abundance in it. A flowchart describing the series of action is given in - Fig. 3 .

\section{Uses of PRF in Pediatric Dentistry}

\section{As Medicament in Pulpotomy}

Patidar et al $^{11}$ conducted a clinical study evaluating PRF and mineral trioxide aggregate (MTA) as a pulpotomy medicament in primary molars. Clinical evaluation was done at 1-, 3- and 6monthsintervals to check symptoms of pain, tenderness to percussion, soft-tissue swelling, pathologic mobility, and sinus formation. Radiological evaluation was performed at an interval of 6 months and considered successful if there was no furcal or periapical radiolucency, no canal calcification, and no internal and external resorption. The findings from this study revealed that PRF can be used successfully as an appropriate alternative material in pulpotomy of primary teeth. Manhas et $\mathrm{al}^{12}$ in a clinical study evaluated and compared PRF as pulp dressing material in primary molar pulpotomy. The current study evaluates MTA, PRF + MTA, and PRF $+\mathrm{Ca}(\mathrm{OH})_{2}$ as a pulpotomy medicament in primary molars at 1-, 3-, and 6months followed by clinical and radiographic assessment. It was concluded that there is a favorable future for PRF in the specialty of deciduous tooth vital pulp therapy.

\section{In Apexogenesis of Young Permanent Teeth}

Mittal et $\mathrm{al}^{13}$ evaluated the regenerative ability of PRF and artificial scaffolds in dying incomplete root development of permanent teeth, and observed that PRF and collagen are superior scaffolds to chitosan and placentrex for apexogenesis. Hongbing et $\mathrm{al}^{14}$ conducted a retrospective controlled study and concluded that using PRF as scaffold for revascularization achieved similar results compared with the technique of inducing periapical bleeding with regard to the healing of the periapical lesion, continued root formation and resolution of clinical signs and symptoms. ${ }^{15,16}$ A systematic review conducted by Miron et $\mathrm{al}^{17}$ evaluated 7 in vitro, 11 in vivo, and 31 clinical studies. As much as 100\% of the in vivo studies and $85.7 \%$ of the in vitro studies affirmed a statistically significant superiority for combining PRF with regenerative treatments. As much as $87 \%$ clinical studies suggested the use of PRF for the regeneration of tissues and wound healing for various treatment procedures in dentistry. ${ }^{18,19}$

\section{As a Pulp Capping Material}

According to Bakshi et al, ${ }^{20}$ PRF showed promising results when used as a direct pulp capping medicament, compared with MTA. Dou et $\mathrm{al}^{21}$ conducted a study to investigate the effect of $\mathrm{Ca}(\mathrm{OH})_{2}$, MTA, iRoot BP, PRF and concentrated growth factors (CGF) on the proliferation, viability, apoptosis, and mineralization of human dental pulp cells and concluded that PRF and CGF are potential pulp-capping materials for vital pulp therapy. However, further studies on the potency of PRF and CGF as vital pulp-capping material and in vivo studies are necessary. ${ }^{22-25}$

\section{For Surgical or Extraction Wound Closure}

PRF is a well-known to have wound healing and regenerative properties, which can used to enhance the healing of surgical wound after cyst or any other defect that causes a large amount of bone loss. In such cases, PRF can be mixed with bone graft and can be packed to the surgical site, in order to enhance healing in children (-Fig. 4). ${ }^{26-29}$ 


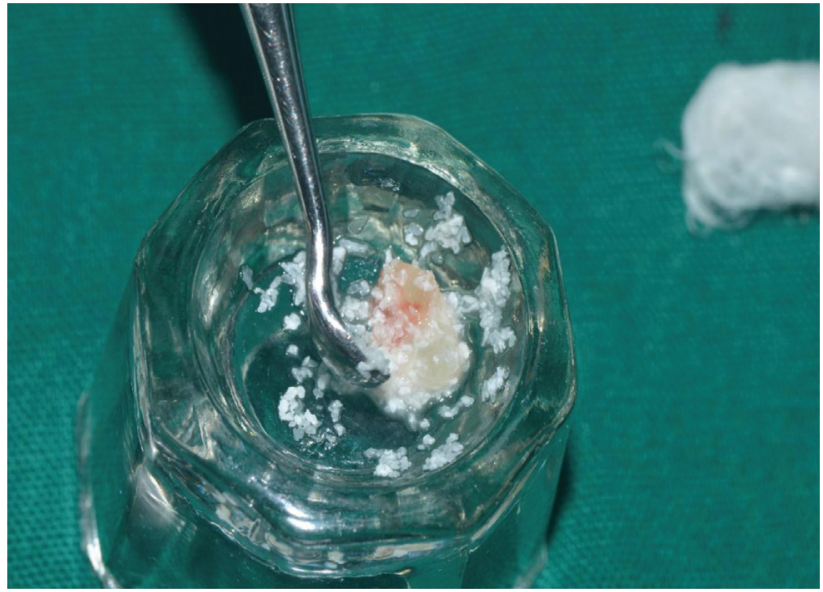

Fig. 4 Platelet-rich fibrin mixed with bone graft ready for loading in surgical site.

\section{Limitation of PRF in Pediatric Dentistry}

- PRF cannot be used to fill large defects in case of cysts. Since autologous blood sample is used to obtain PRF, the quantities produced are low. ${ }^{30,31}$

- Allogenic graft tissue is impractical, since PRF membranes are highly specific to the donor. ${ }^{32,33}$

- Preserving PRF is not feasible, as it will result in shrinkage due to dehydration and modification of the structural integrity as well as reduced growth factor content in PRF. ${ }^{34}$

\section{Advantages of PRF}

- No biological handling of blood.

- Simplified and cost-effective process.

- Anticoagulants not required.

- Favorable healing due to slow polymerization.

- More efficient cell migration and proliferation.

- PRF has supportive effect on immune system.

\section{Disadvantages of PRF}

- Amount available is low, because of autologous blood.

- Quick handling of blood is needed, immediately after collection.

- Drawing blood from pediatric patients is the major difficulty encountered in this procedure, since children are generally apprehensive to needles.

\section{Conclusion}

This article edifies the application of PRF in pediatric dentistry. PRF has been in use for over a decade in regenerative endodontics with an abundance of literature explaining its effectiveness; however, very less or few studies have been conducted on its use in primary dentition and young permanent teeth. Although PRF is found to be a promising material, there is vital need for clinical studies on the primary dentition to support its use, clinical efficacy, and long-term stability in pediatric patients.

\section{Authors' Contributions}

All the authors contributed equally to the study. S.G. made substantial contributions to conception and design and was involved in drafting the manuscript and revising it critically for important intellectual content. S.S. made substantial contributions to conception and design, acquisition of data, and analysis and interpretation of data, besides providing the final approval of the version to be published. S.B.M. made substantial contributions to conception and design, acquisition of data, analysis and interpretation of data, besides providing the final approval of the version to be published. G.B. made substantial contributions to conception and design and revised it critically for important intellectual content. V.V. made substantial contributions to conception and design and revised it critically for important intellectual content.

\section{Conflict of Interest}

None declared.

\section{References}

1 Choukroun J, Adda F, Schoeffler C, Vervelle A. Une opportunité en paro-implantologie: le PRF. Implantodontie 2000;42:55-62

2 Dohan DM, Choukroun J, Diss A, et al. Platelet-rich fibrin (PRF): a second-generation platelet concentrate. Part II: platelet-related biologic features. Oral Surg Oral Med Oral Pathol Oral Radiol Endod 2006;101(03):e45-e50

3 Harrison P. Platelet function analysis. Blood Rev 2005;19(02): 111-123

4 Khiste SV, Naik Tari R. Platelet-rich fibrin as a biofuel for tissue regeneration. Int Sch Res Notices 2013

5 Borie E, Oliví DG, Orsi IA, et al. Platelet-rich fibrin application in dentistry: a literature review. Int J Clin Exp Med 2015;8(05): 7922-7929

6 Gassling VL, Açil Y, Springer IN, Hubert N, Wiltfang J. Platelet-rich plasma and platelet-rich fibrin in human cell culture. Oral Surg Oral Med Oral Pathol Oral Radiol Endod 2009;108(01):48-55

7 Hotwani K, Sharma K. Platelet rich fibrin - a novel acumen into regenerative endodontic therapy. Restor Dent Endod 2014;39 (01):1-6

8 Chatterjee A, Debnath K. Comparative evaluation of growth factors from platelet concentrates: an in vitro study. J Indian Soc Periodontol 2019;23(04):322-328

9 Fernández-Delgado N, Hernández-Ramírez P, Forrellat-Barrios M. Platelet functional spectrum: from hemostasis to regenerative medicine. Rev Cuba Hematol Immunol Hemoter 2012; 28:200-216

10 Wu CL, Lee SS, Tsai CH, Lu KH, Zhao JH, Chang YC. Platelet-rich fibrin increases cell attachment, proliferation and collagen-related protein expression of human osteoblasts. Aust Dent J 2012;57 (02):207-212

11 Patidar S, Kalra N, Khatri A, Tyagi R. Clinical and radiographic comparison of platelet-rich fibrin and mineral trioxide aggregate as pulpotomy agents in primary molars. J Indian Soc Pedod Prev Dent 2017;35(04):367-373

12 Manhas M, Mittal S, Sharma AK, Gupta KK, Pathania V, Thakur V. Biological approach in repair of partially inflamed dental pulp using second-generation platelet-rich fibrin and mineral trioxide aggregate as a pulp medicament in primary molars. J Indian Soc Pedod Prev Dent 2019;37(04):399-404

13 Mittal N, Parashar V. Regenerative evaluation of immature roots using prf and artificial scaffolds in necrotic permanent teeth: a clinical study. J Contemp Dent Pract 2019;20(06):720-726 
$14 \mathrm{Lv} \mathrm{H}$, Chen Y, Cai Z, et al. The efficacy of platelet-rich fibrin as a scaffold in regenerative endodontic treatment: a retrospective controlled cohort study. BMC Oral Health 2018;18(01):139

15 Kiran NK, Mukunda KS, Tilak Raj TN. Platelet concentrates: a promising innovation in dentistry. J Dent Sci Res 2011;2:50-61

16 Gupta V, Bains BK, Singh GP, Mathur A, Bains R. Regenerative potential of platelet rich fibrin in dentistry: Literature review. Asian J Oral Health Allied Sci 2011;1:22-28

17 Miron RJ, Fujioka-Kobayashi M, Bishara M, Zhang Y, Hernandez M, Choukroun J. Platelet-rich fibrin and soft tissue wound healing: a systematic review. Tissue Eng Part B Rev 2017;23(01):83-99

18 Keswani D, Pandey RK. Revascularization of an immature tooth with a necrotic pulp using platelet-rich fibrin: a case report. Int Endod J 2013;46(11):1096-1104

19 Lauricella AM. Fibrin network variability. Acta Bioquim Clin Latinoam 2007;41:7-19

20 Bakshi C, Bogra P, Singh SV, Gupta S, Makhija C. PRF in vital pulp therapy: case report. Baba Farid Univ Dent J 2017;7(01):61-66

21 Dou L, Yan Q Yang D. Effect of five dental pulp capping agents on cell proliferation, viability, apoptosis and mineralization of human dental pulp cells. Exp Ther Med 2020;19(03):2377-2383

22 Maniyar N, Sarode GS, Sarode SC, Shah J. Platelet-Rich fibrin: A "wonder material" in advanced surgical dentistry. Medical Journal of Dr. DY Patil Vidyapeeth 2018;11(04):287

23 Agrawal M, Agrawal V. Platelet rich fibrin and its applications in dentistry-A review article. Natl J Med Dent Res 2014;2(03):51

24 Preeja C, Arun S. Platelet-rich fibrin: Its role in periodontal regeneration. Saudi J Dent Res 2014;5(02):117-122

25 Ghanaati S, Herrera-Vizcaino C, Al-Maawi S, et al. Fifteen years of platelet rich fibrin in dentistry and oromaxillofacial surgery: how high is the level of scientific evidence? J Oral Implantol 2018;44 (06):471-492

26 Singer AJ, Clark RA. Cutaneous wound healing. N Engl J Med 1999; 341(10):738-746

27 Laurens N, Koolwijk P, de Maat MP. Fibrin structure and wound healing. J Thromb Haemost 2006;4(05):932-939

28 Girish Rao S, Bhat P, Nagesh KS, et al. Bone regeneration in extraction sockets with autologous platelet rich fibrin gel. J Maxillofac Oral Surg 2013;12(01):11-16

29 Del Corso M, Toffler M, Dohan Ehrenfest DM. Use of an autologous leukocyte and platelet-rich fibrin (L-PRF) membrane in postavulsion sites: an overview of Choukroun's PRF. J Implant Adv Clin Dent 2010;1:27-35

30 Bansal S, Garg A, Khurana R, Chhabra P. Platelet-rich fibrin or platelet-rich plasma-which one is better? an opinion. Indian J Dent Sci 2017;9(05):49

31 Choukroun J, Diss A, Simonpieri A, et al. Platelet-rich fibrin (PRF): a second-generation platelet concentrate. Part IV: clinical effects on tissue healing. Oral Surg Oral Med Oral Pathol Oral Radiol Endod 2006;101(03):e56-e60

32 Sehgal M, Puri L, Yadav S, et al. Immediate dental implants enriched with L-PRF in the esthetic zone. Case Rep Dent 2018; 2018:9867402

33 Huang FM, Yang SF, Zhao JH, Chang YC. Platelet-rich fibrin increases proliferation and differentiation of human dental pulp cells. J Endod 2010;36(10):1628-1632

34 Clipet F, Tricot S, Alno N, et al. In vitro effects of Choukroun's platelet-rich fibrin conditioned medium on 3 different cell lines implicated in dental implantology. Implant Dent 2012;21(01): 51-56 